Vol. 4, $\mathrm{N}^{\circ} 1 .$, p.95-115 enero - marzo, 2020

Recibido: 06-11-2019/Aceptado: 09-12-2019/ Publicado: 04-01-2020

\title{
El nuevo modelo económico establecido en el Ecuador
}

\section{The new economic model established in Ecuador}

Adriana Margarita Morales Noriega. ${ }^{1}$, Lenin Agustín Chamba Bastidas. ${ }^{2}$, José Luis Moreno Lara. $^{3}$ \& Gladys Verónica Morales Noriega. ${ }^{4}$

\section{DOI: https://doi.org/10.33262/visionariodigital.v4i1.1107}

\begin{abstract}
The purpose of this article is to analyze the economic system established in the country since 2008, up to the economic reforms proposed during the first half of 2019. The political constitutional proposals that have been established during these periods have sought a balance between the state and the Ecuadorians rights, to achieve a sustainable growth levels that allow the population development. However, once the two presidential periods have been analyzed through macroeconomic statistics and social indicators, the Ecuadorian economy has not yet been able to locate an adequate development point, which allows the public and private sector work together in order to have a favorable development from the public policies for the Ecuadorian population. It is evident that in the economic model established in Ecuador, governments have sought a relationship between social sense and economic development in order to achieve the economic growth and help all economic sectors to develop. However, the political action has not yet shown a solid and adequate model, since development level have not reached to the entire Ecuadorian population.
\end{abstract}

Keywords: Economic model, Economic development, Economic policy, Social and solidarity system.

${ }^{1}$ Escuela Superior Politécnica de Chimborazo, adriana.morales@espoch.edu.ec

${ }^{2}$ Escuela Superior Politécnica de Chimborazo, lenin.chamba@espoch.edu.ec

${ }^{3}$ Escuela Superior Politécnica de Chimborazo, jlmorenol@espoch.edu.ec

${ }^{4}$ Cooperativa de Ahorro y Crédito Riobamba Ltda., planificacion@cooprio.fin.ec 
ISSN: 2602-8506

Vol. 4, $\mathrm{N}^{\circ} 1$., p.95-115 enero - marzo, 2020

\section{Resumen}

El presente artículo tiene como finalidad analizar el sistema económico establecido en el país a partir del año 2008, hasta las reformas económicas propuestas durante el primer semestre del año 2019. Las propuestas políticas - constitucionales que se han establecido durante estos períodos han buscado un equilibrio entre el estado y los derechos de los y las ecuatorianas, con la finalidad de contar con niveles de crecimiento sostenibles que permitan el desarrollo de la población. Sin embargo, una vez analizados los dos períodos presidenciales a través de estadísticas macroeconómicas e indicadores sociales, se evidencia que la economía ecuatoriana aún no ha podido localizar un punto de desarrollo adecuado que permita el trabajo en conjunto entre el sector público y el sector privado y de esta manera establecer políticas públicas que fundamente el desarrollo de la población ecuatoriana en condiciones de inclusión favorables para todos los sectores. En el país se evidencia que, en el modelo económico establecido, los gobiernos han buscado relacionar el sentido social con el desarrollo económico, esto con la finalidad de buscar que la economía crezca, se desarrolle y favorezca a todos los sectores económicos de la población, sin embargo, aún el accionar político no ha demostrado que el modelo es sólido y adecuado, ya que los niveles de desarrollo no han llegado a toda la población ecuatoriana.

Palabras claves: Modelo económico, Desarrollo económico, Política económica, Sistema social y solidario.

\section{Introducción}

El Ecuador con la finalidad de obtener mejores resultados en el ámbito económico y social, a través de la historia ha adoptado distintos modelos económicos que permitan la eliminación de las diferencias entre las clases sociales y poderíos económicos; entre los modelos económicos adoptados se encuentran los siguientes: prehispánico, colonial, agroexportador, desarrollista y neoliberalista, cada uno de ellos tenía objetivos distintos a los ya establecidos, su finalidad era el alcanzar un mejor desarrollo para la población ecuatoriana. A pesar de que cada uno de los modelos actuaban en diferentes ámbitos, con el pasar de los años todos demostraron ser planteados bajo la misma visión, ya que la población de los sectores vulnerables seguía sin ser considerada en las actividades políticas y económicas del país, es decir, no existía una participación democrática de todos los sectores, lo cual limitaba el crecimiento y desarrollo económico del país. 
ISSN: 2602-8506

Vol. 4, $\mathrm{N}^{\circ} 1 .$, p.95-115 enero - marzo, 2020

Otra consecuencia derivada de la adopción de los distintos modelos económicos en el Ecuador ha sido la incontrolable extracción de recursos y la salida descontrolada del talento humano; lo cual ha ocasionado severas crisis económicas. La pérdida de la soberanía en el país, así como también los altos índices de subempleo y desempleo han sido una constante en los últimos tiempos, ya que loa medio de producción monopolistas proliferaron y favorecieron a que la riqueza se concentre en pocas manos; así como también ha permitido la concentración de poder político en grandes grupos económicos que pretendían el control de la economía ecuatoriana. Ante esta situación, los niveles de desarrollo económico fueron relativamente bajos y la pobreza cada vez iba incrementándose, lo cual limitó el crecimiento económico ecuatoriano, la riqueza del Ecuador no pudo llegar hacia todos y todas, pues no existió ni existe hasta la actualidad una adecuada redistribución de los recursos que el país posee. El establecimiento de políticas públicas aún necesita considerar las características propias de la población.

El modelo económico neoliberal específicamente, ha sido el limitante para el desarrollo de la economía ecuatoriana, debido a que las políticas públicas adoptadas no consideraban a los diferentes sectores de la economía ecuatoriana y la población lo único que debía hacer era adaptarse a ellas, pese a las desigualdades que ocasionaban. Las políticas neoliberales centraron su accionar hacia el desarrollo de las corporaciones, ya que se permitió las privatizaciones y también hubo recortes en el gasto social. Hasta ese entonces, el Estado no había implementado adecuadamente las políticas socioeconómicas, pues cada vez la brecha económica se iba ampliando y los sectores vulnerables se encontraban sujetos a limitar su crecimiento a las decisiones políticas. En este punto, es necesario considerar que, si un país quiere crecer y desarrollarse adecuadamente, necesita desarrollar políticas públicas participativas y democráticas, es decir, que considere los aspectos sociales, culturales, políticos, territoriales y sociales.

Una economía al momento de implementar un modelo de desarrollo económico debe considerar a todos los sectores económicos existentes, grandes y medianos grupos económicos y también aquellos pequeños segmentos productivos; una vez identificados se tendrá la capacidad de implementar políticas económicas incluyentes que permitan la redistribución de los distintos bienes y servicios para lograr la satisfacción de las necesidades, respetando así el derecho que todos los ciudadanos poseen. Una economía tiene como rol principal la garantía de acceso por parte de la población a todos los recursos independientemente del nivel económico que posea. 
ISSN: 2602-8506

Vol. 4, $\mathrm{N}^{\circ} 1 .$, p.95-115 enero - marzo, 2020

Ante las desigualdades políticas y económicas generadas en el país por varios años, surge la necesidad de redactar una Nueva Constitución para el Ecuador, la cual fue aprobada mediante Consulta Popular y fue puesta en vigencia a partir del 2008. En esta Constitución se reconoce el sistema económico del Ecuador como social y solidario, el cual busca proteger a los medianos y pequeños sectores de la economía ecuatoriana. El punto central de declarar al sistema económico como social y solidario es que el mismo forme parte del régimen de desarrollo (Saldaña, 2015), al cual se lo define como un conjunto organizado, sostenible y dinámico de los sistemas económicos, políticos, socioculturales y ambientales, que garantizan la realización del buen vivir, del sumak kawsay $^{5}$ (Asamblea Nacional, 2008)

\section{REVISIÓN DE LITERATURA}

\section{Política económica}

La política económica es el conjunto de medidas, procedimientos e instrumentos que se aplican en una economía mediante el sistema político, con la finalidad de alcanzar un nivel de crecimiento económico adecuado. (Cuadrado, 2016). El poder ejecutivo en conjunto con las administraciones centrales, son los encargados de establecer las políticas adecuadas con la finalidad de impulsar una economía; esto a través del establecimiento de planes estratégicos que permitan identificar el accionar correcto del gobierno para acceder al control de una economía con la finalidad de generar bienestar y crecimiento económico. (Navarrete, 2012).

La política económica se define como el conjunto de normas a través de las cuales el Estado busca orientar las acciones económicas de un país con la finalidad que exista un desenvolvimiento económico en los aspectos sociales, sectoriales y regionales. En la política económica se analizan los aspectos macroeconómicos de tipo fiscal, monetario y financiero para generar un mercado de equilibrio en el cual exista niveles de crecimiento adecuados y estabilidad política y monetaria. (Blanchard, 2017). El empleo es una de las variables centrales que la población de un país demanda, ya que un nivel de pleno empleo permite la satisfacción de las necesidades, razón por la cual la primera obligación del Gobierno es garantizar el pleno empleo a todos sus habitantes. (Stiglitz, 2016).

${ }^{5}$ El Sumak Kawsay busca el desarrollo de modelos que permitan la mejorar de las relaciones del ser humano con la sociedad, consigo mismo y con la naturaleza, es decir, mediante el Buen Vivir se plantea que el hombre pueda mejorar su nivel de vida y generar un mayor bienestar social. 
ISSN: 2602-8506

Vol. 4, $\mathrm{N}^{\circ} 1 .$, p.95-115 enero - marzo, 2020

El desarrollo integral de una economía debe ser garantizado por medio del establecimiento de una política económica adecuada, ya que su accionar debe centrarse en el mejoramiento de la calidad de vida de su población; en este punto, la política económica se convierte en un factor determinante para generar un ambiente democrático en el país. El direccionamiento de la política económica se encuentra bajo la administración de los organismos gubernamentales, sin embargo, es necesario que se tome en consideración a todos los sectores de la sociedad teniendo en cuenta todas las necesidades que la población posea, ya que de esta manera se podrán establecer los programas y políticas económicas correctas.

La política económica debe generar una eficacia en el ámbito productivo, es decir debe promover el crecimiento económico a través del incremento de la productividad de su población, con lo cual genera empleo y así la población puede alcanzar un mejor bienestar. El Estado también debe eliminar las desigualdades sociales entre los distintos sectores productivos mediante la generación de una economía estable en la cual se minimicen los efectos cíclicos que una economía puede provocar. Por otro lado, es necesario que la política económica evite que el accionar productivo provoque efectos negativos a la sostenibilidad económica que una economía mantiene. Debido a que la política económica pretende generar estabilidad en el nivel de precios, equilibrio frente a la economía internacional, una adecuada redistribución equitativa de la riqueza, crecimiento económico y pleno empleo; el gobierno de un país debe buscar los elementos necesarios para el correcto accionar de esta política, uno de ellos es la adecuada adopción de un modelo económico que permita alcanzar un verdadero desarrollo integral.

\section{Modelo económico}

Los modelos económicos, son representaciones a nivel técnico y teórico de la realidad que presenta un determinado mercado, los cuales se estudian a través de supuestos, y en ocasiones, con el apoyo de la matemática, con la finalidad de analizar las distintas variables que se presentan en los fenómenos económicos. (Beltrán, 2008). Un modelo económico se analiza mediante supuestos ya que analizar a cada una de las variables económicas resulta bastante complejo, razón por la cual en un modelo económico únicamente se analizan aquellas variables determinantes para el fenómeno económico analizado, ya que de esta manera se estudiará la economía de un país de manera simplificada y con mayor comprensión. 
Un modelo económico es considerado como el conjunto deductivo de teorías, en el cual prevalece la interrelación de las distintas variables que reflejan la realidad económica de un país, mediante un modelo se puede analizar, comprender y predecir las distintas magnitudes que puedan suscitar del accionar de una economía. Cada uno de los modelos económicos que se establezcan en un país necesitan contar con sustento adecuado a nivel microeconómico y a nivel macroeconómico, ya que de esta manera se formularán las políticas económicas adecuadas que permitan generar índices de crecimiento y desarrollo económico apropiados. (Olmedo, 2013)

En el momento en el cual se hace referencia a los modelos económicos como la forma de organizar la actividad económica de un país, se está analizando a los sistemas económicos, los cuales buscan organizar la producción de bienes y servicios, para que sea redistribuida a todos los miembros de una economía. Un sistema económico es el conjunto de relaciones estructurales básicas, de índole técnica e institucional que caracterizan la organización económica total de una sociedad y que determinan el sentido de sus decisiones fundamentales, así como los cauces predominantes de su actividad. (Salas, 2015)

Un sistema económico busca que la población pueda elaborar, comercializar y consumir todos aquellos bienes y servicios que se generan de la actividad económica, con la finalidad que las necesidades ilimitadas de la población sean cubiertas, ante lo cual un sistema económico debe utilizar y aprovechar al máximo los recursos disponibles que dispone; es decir, la economía debe ser lo más eficiente posible en cuanto a aspectos sociales se refiere, ya que si una economía no atiende a los sectores vulnerables no podrá crecer en términos sociales.

\section{Metodología}

La investigación desarrollada es de tipo descriptivo, ya que se analizarán los hechos suscitados en la realidad en relación con el modelo económico y se los analizará e interpretará en base al contexto económico actual. Para validar la investigación, se procederá a considerar los análisis, descripciones e interpretaciones desarrolladas en base al modelo económico existente en nuestro país desde el establecimiento de la Nueva Constitución del Ecuador hasta la propuesta del Plan de Austeridad 2018 - 2021 establecido por el gobierno actual. Esta investigación también será de tipo documental, ya que se realizarán consultas a la Constitución del Ecuador, revistas y libros; con la

finalidad de recopilar información sobre el modelo económico actual del Ecuador. Una vez que se investigue el tema objeto de estudio, se procederá analizar la información respectiva para conocer 
ISSN: 2602-8506

Vol. 4, $\mathrm{N}^{\circ} 1 .$, p.95-115 enero - marzo, 2020

de manera más detallada la influencia del modelo económico en la generación de bienestar en la población ecuatoriana.

\section{Resultados}

\section{Modelo de desarrollo social y solidario}

A partir del 2008, entra en vigor la Nueva Constitución Política del Ecuador, la cual tiene como objetivo primordial el cuidado de los intereses de la población ecuatoriana, aspirando así un Estado más justo, más solidario, en el cual toda la población se encuentre incluida en los procesos de desarrollo que ese lleven a cabo en el país. A través de la Constitución del 2008, se establece un modelo de desarrollo social y solidario que cuenta con un sistema financiero popular y solidario propio. Específicamente en el artículo 283 de la Constitución se instaura que: "El sistema económico es social y solidario; reconoce al ser humano como sujeto y fin; propende a una relación dinámica y equilibrada entre sociedad, Estado y mercado, en armonía con la naturaleza; y tiene por objeto garantizar la producción y reproducción de las condiciones materiales. El sistema económico se integrará por las formas de organización económica pública, privada, mixta, popular y solidaria, y las demás que la Constitución determine. La economía popular y solidaria se regulará de acuerdo con la ley e incluirá a los sectores cooperativistas, asociativos y comunitarios." (Constitución de la República del Ecuador, 2008)

Debido al reconocimiento de la forma de organización económica popular y solidaria, el artículo 311 de la Constitución establece "El sector financiero popular y solidario se compondrá de cooperativas de ahorro y crédito, entidades asociativas o solidarias, cajas y bancos comunales, cajas de ahorro. Las iniciativas de servicios del sector financiero popular y solidario, y del micro, pequeñas y medianas unidades productivas, recibirán un tratamiento diferenciado y preferencial del Estado, en la medida en que impulsen el desarrollo de la economía popular y solidaria." (Constitución de la República del Ecuador, 2008)

El reconocimiento de un modelo económico social y solidario pretende que todas las familias ecuatorianas alcancen un bien común, es decir, se llegue a un bienestar en el cual el capital ya no sea el factor que prevalezca al momento de desarrollar las distintas actividades, sino que exista una valoración prioritaria hacia el trabajo. Las políticas públicas que el país adopte deben priorizar el interés colectivo, es decir el interés de cada uno de los sectores productivos del Ecuador, antes del interés individual. (Trujillo, 2007). Se pretende también que exista una intervención mayor 
por parte del estado en las actividades políticas y económicas, con la aspiración de favorecer a los sectores sociales en estado de exclusión. La población ecuatoriana debe ser consciente que el desarrollo integral del país se alcanzará en el momento en el cual exista una responsabilidad social en todos los sectores del territorio, es decir, exista un interés de alcanzar niveles de desarrollo para todos los sectores productivos y no únicamente favorecer el desarrollo de ciertos grupos de poder económico tradicionales en la economía ecuatoriana.

La declaratoria de un sistema económico social y solidario posee también tres características: 1. Reconocimiento al ser humano como sujeto y fin. 2. Propende a una relación dinámica y equilibrada entre sociedad, Estado y mercado, en armonía con la naturaleza. 3. Garantiza la producción y reproducción de las condiciones materiales e inmateriales que posibiliten el buen vivir. (Saldaña, 2015). Otro de los deberes fundamentales que mantiene el Estado con relación al Buen Vivir, es el impulso de actividades productivas a través de instancias gubernamentales que las promuevan, fomenten y respalden el desarrollo (Artículo 277 de la Constitución Política del Ecuador 2008. Título sexto: Régimen de desarrollo. Capítulo primero: Principios Generales) y así alcanzar espacios en los cuales se favorezca el desarrollo de la fuerza laboral y así garantizar el pleno empleo de la sociedad ecuatoriana.

El Buen Vivir acorde a la Constitución del 2008, se presenta como un derecho adquirido por la sociedad para contar con espacio sanos, en los cuales exista el total acceso hacia la educación, vivienda, salud y seguridad social; es decir este derecho debe ser garantizado por el Estado ecuatoriano mediante el desarrollo de prácticas equitativas e inclusivas.

El camino constitucional hacia un modelo de desarrollo social y solidario se encuentra establecido, sin embargo, la política económica del Ecuador se sitúa como la responsable de alcanzar el equilibrio entre el trabajo, la producción y el medio ambiente. (Acosta, 2014). Es necesario existan cambios en todo el ciclo económico: la producción, la reproducción, la distribución y el consumo, lo cual determina el camino hacia una nueva matriz productiva; a su vez evidencia el paso de un esquema primario exportador y extractivista a uno que privilegie la producción diversificada y ecoeficiente, así como los servicios basados en los conocimientos y la biodiversidad. (Secretaria Nacional de Planificación y Desarrollo, 2017). El artículo 280 de la Constitución del Ecuador establece que: "EI Plan Nacional de Desarrollo es el instrumento al que se sujetarán las políticas, programas y proyectos públicos; la programación y ejecución del presupuesto del Estado; y la 
ISSN: 2602-8506

Vol. 4, $\mathrm{N}^{\circ} 1 .$, p.95-115 enero - marzo, 2020

inversión y la asignación de los recursos públicos; y coordinar las competencias exclusivas entre el Estado central y los gobiernos autónomos descentralizados. Su observancia será de carácter obligatorio para el sector público e indicativo para los demás sectores.” Ante esta situación se establece al Plan Nacional de Desarrollo como un instrumento que permite la construcción de un Estado más justo, incluyente y participativo, con la finalidad de alcanzar un nivel de desarrollo para todos los sectores de la economía ecuatoriana.

\section{Plan nacional de desarrollo}

El modelo económico social y solidario podrá ser alcanzado por parte del Estado ecuatoriano una vez que exista el reconocimiento de las bases de la economía, es decir, se tenga en cuenta cada una de las diversas formas de producción, ya que cada una de ellas tiene la finalidad de brindar los recursos necesarios para lograr el desarrollo económico. El país, tiene distintos métodos de producción, sobre todo aquellos métodos productivos locales que sustentan su accionar en prácticas solidarias con un amplio sentido de cooperación, los cuales buscan la conservación de los recursos naturales y saberes; gracias a los cuales se ha logrado desarrollar una producción sin la búsqueda de acumulación de capitales. (Acosta, 2008).

Bajo el modelo de desarrollo económico actual del Ecuador se pretende el acceso por parte de la población a los recursos disponibles de manera equitativa, es decir, sin exclusión alguna; ya que el rol del estado no únicamente debe centrarse en la regulación de la economía, sino que también debe direccionar la actividad económica y redistribuirlas entre todos los ciudadanos.

A través del establecimiento del Plan Nacional de Desarrollo, busca fortalecer el sistema económico mediante la búsqueda de un equilibrio de vida en el cual haya verdaderas condiciones de justicia y también soberanía. En este plan se busca que el ser humano sea el sujeto y fin de todo tipo de actividad económico, mediante el reconocimiento de la diversidad económica. (Secretaria Nacional de Planificación y Desarrollo, 2017). El sistema económico establecido en el país permite la sustentabilidad de cada uno de los sectores económicos, ya que pretende aportar al mejoramiento de la calidad.

\section{Política económica período 2007 - 2017}

El accionar económico en el período de la Revolución Ciudadana se direccionaba a la inversión pública y al gasto público como pilares fundamentales en la generación de crecimiento económico, los objetivos fundamentales que perseguía la política económica del gobierno de Correa eran los 
siguientes: 1) Desplegar la productividad nacional de manera sustentable, la cual permita la satisfacción de las necesidades de la población y también la finalidad de este objetivo es la potencialización de la economía familiar, asociativa, comunitaria y territorial; 2) Crear fuentes de empleo estables, en las cuales se reconozca y valore al capital humano como motor de desarrollo económico, en este sentido se debe primar la importancia que tiene el ser humano sobre el capital económico; 3) Posicionar los procesos de integración comercial para afianzar las alianzas comerciales a nivel internacional que permitan que la economía ecuatoriana sea reconocida por el resto de países; 4) Lograr niveles de inclusión social en la cual exista una adecuada redistribución del nivel de riqueza ecuatoriana, llegando así a disminuir las desigualdades económicas y las injusticias sociales; 5) Mediante la participación ciudadana y la cohesión social se busca que la población ecuatoriana confíe el accionar de las políticas económicas establecidas por el gobierno. (Jácome, 2007).

Una vez establecidos los lineamientos del modelo económico, es necesario que se impulsen los instrumentos de política económica adecuados, entre los cuales se mencionan los siguientes: 1) la política de producción como herramienta de fomento del sector real; 2) el fortalecimiento del sector externo, mediante el desarrollo de la política comercial de integración; 3) la dinamización de la economía local y nacional, a través del establecimiento de una política fiscal expansiva; 4) el desarrollo de una política financiera que sea capaz de garantizar el acceso al crédito a todos los sectores de la población; 5) reducción de la brecha económica existente a través de la política social; cada una de estas políticas buscan brindar mayor bienestar a la población. Estas políticas también evidencian el rol del estado como un organismo que a través de la planificación y la regulación promueven un bienestar social y económico para sus habitantes. (García, 2015).

La política de desarrollo económico, durante los diez años de mandato presidencial de Rafael Correa, buscaba la generación de empleos directos en el sector público, por otro lado, se pretendía mediante esta política, generar un nivel de gasto público en el cual exista la formación del capital fijo, esto a través de la inversión en sueldos y salarios, una mejoría en la infraestructura estatal, lo cual se evidencia en el mantenimiento de los hospitales, establecimientos educativos. Es evidente que durante esta época se dictaminaron una serie de políticas con la finalidad de lograr un mayor bienestar en la población ecuatoriana, a través de la atención prioritaria de la salud, la educación y la satisfacción de las necesidades básicas. Las políticas económicas establecidas direccionaban el 
nivel de gasto público hacia la generación de un nivel de crecimiento económico progresivo, inclusivo, justo y socialmente responsable. El resultado de la implementación de dichas políticas se ha direccionado, en un largo plazo, hacia la obtención de resultados sociales positivos, en los cuales se visibilice la reducción del nivel de pobreza nacional y también exista la cobertura de salud y educación de los sectores económicos tradicionalmente excluidos. (Martínez, 2017).

Por otro lado, la política económica establecida buscaba ser productiva, en este sentido se estableció una visión de accesibilidad democrática hacia los factores de producción y de los insumos de producción; lo cual se ha llevado a cabo mediante un análisis exhaustivo hacia la disminución de aranceles de los bienes de capital e insumos de producción; logrando así un desarrollo más integral del sector agrícola del Ecuador. Las políticas desarrolladas han actuado en el ámbito tributario, en el cual se ha dado prioridad a los impuestos directos en lugar de los impuestos indirectos; la finalidad de la priorización tributaria es el fomento de la producción nacional y la eficiencia en el ámbito de recaudación tributaria. En el aspecto financiero, ha existido una mayor asignación de recursos para el desarrollo de la banca pública, con la finalidad de fortalecer el sistema financiero público y dar paso al acceso crediticio para las personas excluidas del sistema financiero tradicional, lo cual ha sido una problemática común en Ecuador.

Se ha implementado por otro lado, un sistema financiero popular y solidario, el cual busca el desarrollo de aquellos sectores productivos pequeños, a través del financiamiento en las Cooperativas de Ahorro y Crédito. Este sistema se encuentra amparado bajo la Ley Orgánica de Economía Popular y Solidaria, en la cual se entiende a la economía popular y solidaria como: “forma de organización económica donde sus integrantes, individual o colectivamente, organizan y desarrollan procesos de producción, intercambio, comercialización, financiamiento y consumo de bienes y servicios, para satisfacer necesidades y generar ingresos, basadas en relaciones de solidaridad, cooperación y reciprocidad, privilegiando al trabajo y al ser humano como sujeto y fin de su actividad, orientada al buen vivir, en armonía con la naturaleza, por sobre la apropiación, de lucro y acumulación de capital (Ley Orgánica de la Economía Popular y Solidaria y del Sector Financiero Popular y Solidario)." El objetico de esta normativa es incentivar el desarrollo de pequeños y medianos empresarios, ya que los mismos mediante el desarrollo de las actividades económicas, buscan generar recursos que apoyen la capitalización, la acumulación y sobre todo la sobre vivencia de su sector económico. Este estatuto expedido en el Ecuador busca por otro lado, 
reconocer como eje de desarrollo económico al sector de la economía informal, ya que tiene una representatividad de cerca del $20 \%$ en el mercado laboral del Ecuador. Las Cooperativas de Ahorro y Crédito son las más representativas dentro de este sistema, ya que desarrollan sus actividades bajo los lineamientos de la cooperación y la solidaridad, lo cual permite que cada vez más personas sean incluidas en el sistema financiero; en la actualidad las entidades cooperativas en el Ecuador captan aproximadamente 4.200 millones de dólares, lo cual resulta ser representativo en la economía nacional.

En el ámbito laboral, esta adopción de modelo económico tiene como aspiración la abolición de los altos índices de desempleo, mediante la creación de oportunidades laborales estables y sustentables; por otro lado, también se brinda apoyo hacia aquellas actividades nuevas, es decir los emprendimientos, los cuales son una oportunidad de autoempleo. El apoyo del gobierno a los emprendimientos es a través del acceso al crédito productivo aquellos sectores micro, pequeños y medianos para crear un mercado laboral con pleno, en el cual los miembros de la producción económicamente activan puedan generar ingresos que les permita acceder a los recursos necesario que requieren para lograr un nivel de desarrollo adecuado.

La estrategia económica durante el período analizado se fundamentó en fortalecer el papel del Estado con la finalidad de alcanzar un mejor desarrollo en la economía ecuatoriana, a través de la potenciación de la política social y el gasto corriente. Las medidas económicas desarrolladas en el período analizado influyeron positivamente, ya que las condiciones de vida de la población mejoraron, lo cual se evidencia en la reducción de la pobreza, que pasó del $26 \%$ al $17 \%$, el desempleo se redujo al 5\%, en el ámbito educativo el nivel de gasto pasó del 3,6\% del PIB al 5,3\% del PIB, en el ámbito de salud el gasto se incrementó del 1,3\% del PIB al 1,8\% del PIB y en el aspecto de la seguridad social, el $37 \%$ de la PEA se afilió ya que la normativa buscaba que los trabajadores posean mayores beneficios. (Mosquera \& Vaca, 2014)

Los datos macroeconómicos analizados, evidencian que las medidas económicas implementadas buscaban que la población ecuatoriana alcanzara un mayor bienestar, de hecho, las condiciones de vida mejoraron gracias al entorno político adecuado que existía durante el primer período presidencial. El ejecutivo contaba con respaldo en su gestión y gracias a ello se pudieron realizar reformas constitucionales, los contratos petroleros mejoraron, las leyes de comunicación, minería y las reformas tributarias fueron aprobadas; lo cual permitió que la actividad y el crecimiento 
económicos en el país se desarrollen adecuadamente. Por otro lado, durante el período analizado los precios del petróleo alcanzaron niveles máximos que nunca se habían reportado, su crecimiento llegó a representar el 14\% del PIB ecuatoriano; los recursos petroleros percibidos por el estado permitieron la ejecución de obras de infraestructura que durante varios años estuvieron planificadas.

La economía del Ecuador ha podido superar niveles de crecimiento negativos existente durante varios años, debido a que el ejecutivo pudo respaldar sus medidas económicas en la inversión y el gasto público. El gasto del gobierno llegó a crecer en promedio un 7,1\%, sin embargo, a pesar de que los datos macroeconómicos presentados evidencian niveles de crecimiento aceptables, durante esta época no hubo mayor preocupación por establecer políticas económicas en conjunto con el sector productivo privado, por lo cual el crecimiento económico fue momentáneo y no llego a ser sostenible. Las razones por las cuales no se alcanzó un crecimiento sostenible fueron: la recaudación tributaria, el alza de los precios del petróleo y el endeudamiento. Debido a la normativa establecida, el estado pudo recaudar de manera más eficiente y obtener mayores ingresos, lo cuales llegaron a representar el 19\% del PIB ecuatoriano. Por otro lado, los altos precios petroleros dieron paso a que el país percibiera mayores ingresos y finalmente, para respaldar la mayor cantidad de obras en el ámbito de infraestructura, salud, educación, seguridad social, etc., el estado tuvo que recurrir al endeudamiento tanto interno como externo; los mayores financistas del estado fueron el Instituto Ecuatoriano de Seguridad Social, el gobierno chino, el BID y la CAF; el nivel del deuda del Ecuador creció cerca del 26\%, lo cual evidencia que el gobierno para poder sostener su estructura económica - productiva, respaldo su accionar en el financiamiento externo a través de la deuda y así pudo disponer de mayores ingresos para sostener el gasto público corriente. El gobierno direccionó su accionar en la implementación de políticas que permitiesen el desarrollo de toda la sociedad, a través de la mejora en los índices sociales, los cuales es indudable negar que han mejorado, habido reducción en la pobreza pero las zonas rurales continuaron sin poder satisfacer sus necesidades básicas, hubo mayor acceso a la educación y salud pero muchas de las infraestructuras desarrolladas para la prestación de estos servicios únicamente fueron construidas y no contaban con los insumos adecuados que permitieran la prestación de estos servicios de manera eficiente; por ultimo existió también mejoría en las tasas de empleo; sin embargo, la mayoría de los empleos que se implementaron fueron empleos no adecuados en los 
cuales los trabajadores no recibían una remuneración que supere al salario básico. A pesar del incremento porcentual que han reflejado varias cifras económicas, no ha existido una proyección de sostenibilidad a largo plazo, lo cual ha limitado el crecimiento y desarrollo del país.

\section{Aportes de la política económica actual}

El resultado económico una vez culminados los diez años de revolución ciudadana fue la presencia de desequilibrios macroeconómicos, específicamente en el ámbito fiscal y a nivel público, ya que el actual gobierno se encontró con un déficit fiscal de aproximadamente el 5\% del Producto Interno Bruto. Este nivel de déficit ocurrió debido a que en el período de gobierno anterior hubo un excesivo gasto público, el cual fue mayor a los niveles de ingresos de la economía ecuatoriana. Por otro lado, la baja del precio del barril del petróleo provocó una inestabilidad económica, ya que el desarrollo de las actividades económicas se financiaba en gran porcentaje de los ingresos petroleros. El mercado laboral también se ha visto perjudicado, ya que la oferta laboral no ha podido cubrir las necesidades laborales por parte de la población, lo que ha ocasionado reducciones salariales y un incremento en los niveles de subempleo. (Robalino, 2017). En el ámbito productivo, los aranceles impuestos por el gobierno anterior provocaron que las empresas vayan limitando su nivel de productividad, de hecho, una serie de empresas cerraron sus puertas en nuestro país, lo cual limitó el desarrollo de la economía ecuatoriana.

El gobierno de Lenin Moreno recibió a nivel económico un país con aproximadamente una deuda de 60 mil millones de dólares, las medidas económicas que ha tenido que adoptar para hacer frente a la crisis económica que el país enfrenta, han resultado ser insuficientes. El crecimiento económico en el Ecuador empezó a decrecer aproximadamente en un 2,3\%, a consecuencia de la disminución del gasto público, lo cual era necesario realizar para lograr un fortalecimiento de la economía, ya que, al no existir un nivel de ahorro estatal, la capacidad de generar un crecimiento a largo plazo resultaba inexistente. El empleo ecuatoriano ha permanecido en una situación de deterioro, ya que constantemente es mayor el número de ecuatorianos que se quedan sin trabajo, desde el 2014 a inicios del 2018 el nivel de empleo bajo del 49,3\% al 42,3\%, lo cual limitó los ingresos percibidos por las familias ecuatorianas y a su vez ocasionó una contracción en la demanda ya que no existían los ingresos suficientes para adquirir los bienes y servicios suficientes para la satisfacción de las necesidades, es decir, que empezó a suscitarse en el país una situación de deflación ante la caída del IPC. Una situación de deflación para la economía ecuatoriana indica 
que el nivel de endeudamiento ha resultado ser insuficiente para la realización de las distintas actividades para la economía ecuatoriana, ya que las familias no cuentan con un nivel de liquidez apropiado y limita el desarrollo de las actividades productivas. La economía ecuatoriana evidentemente se ha caracterizado por ser dependiente al flujo de dólares provenientes del exterior y débil al momento de que se presentan shocks económicos.

Ante estos desequilibrios macroeconómicos una de las primeras medidas determinadas por el presidente Moreno fue la promulgación de la Ley de Fomento Productivo, el cual busca recuperar los niveles de productividad en el país; en este sentido esta Ley establece el marco regulatorio legal que permita un equilibrio fiscal y también bajos niveles de endeudamiento. En este sentido, la normativa genera las condiciones iniciales para que las actividades productivas desarrollas por los sectores de la economía popular y solidaria fortalezcan la economía ecuatoriana a través de la generación de bienestar para las familias ecuatorianas. El apoyo hacia la generación de adecuados niveles de productividad se reflejan en el momento en el cual existe la exoneración de entre 8 y 20 años del pago del impuesto a la renta: permitiendo así el desarrollo de actividades de emprendimiento que generen plazas de trabajo; es necesario el apoyo hacia la producción, ya que la economía ecuatoriana no puede depender exclusivamente de las entidades públicas, por el contrario, el rol de la economía privada es esencial para impulsar el desarrollo de la economía.

El modelo económico en el país continúa siendo social solidario, sin embargo, el presidente Lenin Moreno para sanar la debilidad económica que el país posee, ha desarrollado un Plan de Prosperidad 2018 - 2021, con la finalidad de garantizar los derechos de los sectores vulnerables y crear mejores condiciones de desarrollo para las futuras generaciones. Entre los puntos principales que se establecen en el Plan de Prosperidad 2018 - 2021 están los siguientes:

Reducción del tamaño del Estado es una necesidad y una prioridad de este Gobierno. Reducción de 20 instituciones entre ministerios, secretarías, institutos y agencias dependientes del Estado.

La estructura del aparato gubernamental ha resultado ser excesiva, existen muchas entidades estatales que no necesarias, lo cual no está permitiendo una atención hacia otros sectores que aún se encuentran desprotegidos; motivo por el cual se procederá a estructurar el poder ejecutivo mediante la fusión de entidades estatales. El impacto de la re estructuración del Estado, permitirán que exista un ahorro de aproximadamente 62 millones de dólares. Es necesario mencionar que las 
competencias de las entidades que lleguen a fusionarse serán trasladadas hacia otras estancias gubernamentales.

\section{Reducción de gastos excesivos}

El gobierno anterior se caracterizó por mantener montos excesivos de gasto, ante lo cual muchos fueron los desequilibrios económicos que se produjeron, razón por la cual es necesario la reducción del gasto, para que el mismo resulte óptimo. Se venderán aquellos bienes públicos que resulten innecesarios al momento de generar desarrollo en el país.

\section{En las Empresas Públicas se llevará a cabo un profundo proceso de optimización}

Las empresas públicas pasarán a ser administradas por los ministerios correspondientes, con la finalidad de contar con una administración adecuada en las actividades que realizan las empresas estatales. Por otro lado, se buscará un equilibrio en los salarios para que exista igualdad de oportunidades entre todos los miembros de la sociedad ecuatoriana.

Lograr sostener la inversión en infraestructura y otros proyectos de desarrollo con recursos del estado y con la colaboración de la inversión privada en el esquema APP en el período 2018-2021. El esquema APP resulta indispensable al momento de desarrollar proyectos, ya que el mismo garantiza procesos adecuados en la generación de la inversión privada, esta inversión en la actualidad es necesaria ya que permite un manejo idóneo de los activos del país. Debido a la importancia que los activos estatales representan para el desarrollo económico en conjunto con el Banco Interamericano de Desarrollo se ha empezado a evaluar a todos los activos disponibles y valorar aquellos que permitan generar ingresos para el país, con la finalidad de volverlos más productivos y así generar mayor bienestar económico.

\section{Fortalecer las reservas del Banco Central del Ecuador y su capacidad técnica.}

El Banco Central es una entidad clave para el proceso económico que se desarrolla en el país, razón por la cual, esta entidad debe garantizar el crecimiento económico y adecuadas tasas de empleo mediante un respaldo adecuado para el sector financiero tanto público como privado, lo cual es posible siempre y cuando la entidad disponga de un nivel de reservas suficiente. Para fortalecer el nivel de reservas del Banco Central se empezará a canjear las acciones de banca pública entregadas en dación de pago, por títulos de deuda pública.

Acceso a financiamiento externo estable, predecible y en mejores condiciones de plazo y tasa de interés. 
ISSN: 2602-8506

Vol. 4, $\mathrm{N}^{\circ} 1 .$, p.95-115 enero - marzo, 2020

El acceso al financiamiento externo resulta apropiado en el momento en el cual se busca una mejor sostenibilidad económica en el país, ya que esta financiación permite cubrir los déficits fiscales excesivas que tiene el país actualmente y también permite la reducción de la brecha fiscal.

Aprovechamiento responsable de nuestros recursos naturales.

El Ecuador se caracteriza por ser una economía portadora de una serie de recursos naturales, los cuales permiten la generación de ingresos, siempre y cuando sean manejados de manera apropiada, es decir, con transparencia. La economía ecuatoriana por los recursos que posee tiene adecuadas posibilidades de exportar sus recursos hacia el exterior, por eso es necesario impulsar la comercialización de productos en el extranjero. La producción petrolera también incrementará sus niveles de productividad y así se generarán mayores ingresos hacia la economía ecuatoriana.

Actualización del precio de la gasolina super - No topar el diésel del transporte. Optimización de subsidio al diésel para el sector empresarial.

Estos lineamientos fueron establecidos con la finalidad de recuperar la economía ecuatoriana, mediante la focalización de los subsidios hacia aquellos sectores que realmente lo necesitan, lo cual representaría un nivel de ahorro adecuado que permitiría la generación de proyectos de desarrollo que permitan el crecimiento de los distintos sectores económicos.

El Plan de Prosperidad presentado por el presidente actual buscan implementar medidas que respalden la dolarización, así como también las medidas buscan el desarrollo de niveles de competitividad adecuados y eficientes. El empleo también busca ser promovido en el país, debido a que de acuerdo al modelo económico establecido el Ecuador mediante la implementación del Buen Vivir debe garantizar el trabajo digno para la población en todas sus formas, motivo por el cual el gobierno ha buscado limitar el aparato estatal como generador de empleo, sino por el contrario buscar el apoyo del sector privado en la generación de empleo con la finalidad de que sean sostenibles y con condiciones adecuadas.

La política económica establecida por el gobierno actual pretende actuar en base a cuatro ejes principalmente: sostenibilidad de la dolarización, equilibrio fiscal, reactivación productiva y la reestructuración del Estado; aunque los niveles de endeudamiento heredados en el actual gobierno continúan siendo altos, el ejecutivo continuar con este tipo de medidas para aliviar la situación de vulnerabilidad en la que se encuentran varias familias del Ecuador. El gobierno actual pretende que el país sea un destino interesante en el ámbito empresarial en el cual se pueda impulsar fuentes 
de empleo adecuadas, se ha empezado a eliminar las barreras que impidan la creación de empresas, por otro lado, también las medidas económicas del actual régimen buscan incentivar la inversión y productividad privada y apertura del comercio internacional. Actualmente los niveles del empleo llegan al 37,9\%, el cual refleja haber disminuido respecto al año anterior que situó en 41,1\%; estas cifras evidencian el problema por el cual el mercado laboral atraviesa, surge entones la necesidad de que el sector privado actúe, tratando de acoger a los empleados que han sido desplazados del sector público debido a la política establecida por el gobierno, la cual busca reducir el gasto gubernamental a través de la reducción de las entidades gubernamentales existentes.

Los indicadores sociales se presenta como un tema de preocupación para este gobierno, ya que aún existe un 3,4\% de la población ecuatoriana que viven con menos de \$1,90 al día, sobre todo en las zonas rurales; el gobierno ha decido incrementar el nivel de gasto destinado para proyectos de asistencia social con la finalidad de ampliar la cobertura de estas asistencias hacia más sectores desprotegidos en el país, los cuales se extenderán siempre y cuando consten en el registro social desarrollado por el estado para direccionar de mejor manera las asistencias sociales que se implementen. El gasto en salud y educación implementado por el actual régimen, pretende sea eficiente y de calidad con el propósito de que el país alcance sus metas económicas y competitivas.

\section{Conclusiones}

Los distintos modelos económicos que se han adoptado en el país a lo largo de la historia han sido establecidos con la finalidad de lograr un desarrollo adecuado para todos los sectores del país, es decir, que existan menos desigualdades, sin embargo, los modelos han demostrado que eran planteados sin considerar la participación democrática de todos los sectores; razón por la cual el Ecuador no ha alcanzado un adecuado crecimiento y desarrollo económico.

El Ecuador en el 2008 establece un nuevo modelo de desarrollo económico, en el cual se prioriza a las personas y a la naturaleza como ejes centrales de su accionar, es así como se establece un sistema económico social y solidario que promueve una relación equilibrada entre sociedad, estado y mercado; los cuales respeten a la naturaleza.

El sistema económico social y solidario fue declarado modelo de desarrollo en el país, con la finalidad de lograr una distribución equitativa de los medios de producción y la consecución de un trabajo digno y estable para toda la población. 
SSN: 2602-8506

Vol. 4, $\mathrm{N}^{\circ} 1$., p.95-115 enero - marzo, 2020

La economía del Ecuador aún no hay podido alcanzar un nivel de desarrollo adecuado, la razón principal radica en que las medidas adoptadas por el régimen no han logrado una conexión entre crecimiento y desarrollo económico, motivo por el cual es necesario que las medidas que el estado implemente considere a todos los sectores de la población sin exclusión alguna.

A pesar de que, durante el periodo de análisis, varias han sido las políticas establecidas por los gobiernos, aún falta que exista una consolidación de las medidas desarrolladas y una medición de la eficiencia de estas, para que haya un real aporte hacia la economía popular y solidaria y así llegar alcanzar el Buen Vivir.

\section{Referencias bibliográficas}

Acosta, A. (2008): “El Buen Vivir, una oportunidad por construir.” Ecuador Debate N75, 33 48.

Acosta, A. (2014). Buen Vivir - Sumak Kawsay. Una oportunidad para imaginar, Icaria, Barcelona.

Artículo 277 de la Constitución Política del Ecuador 2008. Título sexto: Régimen de desarrollo. Capítulo primero: Principios Generales.

Asamblea Nacional. (2008). Constitución de la República del Ecuador. http://www.asambleanacional.gov.ec/documentos/constitucion_de_bolsillo.pdf

Beltrán, L. (2008). Programa de Administración Pública Territorial, http://www.esap.edu.co/portal/wp-content/uploads/2017/10/5-Politica-Economica.pdf

Blanchard, O. (2017). Macroeconomía, $7^{\mathrm{a}}$ ed., Pearson-Prentice Hall, Madrid.

Cuadrado, J. (2016). Política Económica: Elaboración, objetivos e instrumento, Mc Graw Hill, Madrid.

García, S. (2015). "La Identidad de la Política Económica del Gobierno de Correa.”, Academia, http://www.academia.edu/7535229/car\%C3\%A1cter_de_la_pol\%C3\%ADtica_econ\%C3 $\%$

Jacome, H. (2007). La Política Económica del Gobierno de Rafael Correa. La Tendencia, 50 55. 
ISSN: 2602-8506

Vol. 4, $\mathrm{N}^{\circ} 1$., p.95-115 enero - marzo, 2020

Ley Orgánica de la Economía Popular y Solidaria y del Sector Financiero Popular y Solidario.

Martínez, M. (2017). GK., Quito, https://gk.city/2017/09/21/politica-economica-rafael-correa/

Ministerio de Economía y Finanzas. (2018): "Plan de Prosperidad 2018 - 2021", Quito.

Monje, C. A. (2011). Metodología de la Investigación Cuantitativa y Cualitativa, Universidad Sur colombiana, Facultad de Ciencia Humanas y Sociales, Neiva.

Mosquera, R., \& Vaca, L. A. (2014). La era Correa: evaluación macroeconómica 2006 - 2012 y perspectivas. Valor Agregado. Revista para la Docencia de Ciencias Económicas y Administrativas en el Ecuador, 127 - 140.

Navarrete, J. P. (2012). Política Económica, Red tercer milenio S.C., México

Olmedo, O. (2013). Bolivia: modelos económicos y sistema político. Perspectivas. Universidad Católica Boliviana, 133 - 156.

Robalino, C. (2017). Colegio de Economistas de Pichincha, Quito, http://colegiodeeconomistas.org.ec/la-coyuntura-economica-plan-economico-delgobierno-del-lcdo-lenin-moreno/

Salas, F. (2015). Sobre la Libertad y la Economía, CEDICE, Caracas.

Saldaña, J. V. (2015). La Constitución Económica del Ecuador. Iuris Dictio. Revista de Derecho, 121-148.

Saltos, J. G., Mayorga, M. \& Ruso A. (2016). La economía popular y solidaria: un estudio exploratorio del sistema en Ecuador con enfoque de control y fiscalización. Cofin Habana, 10(2), 55-75. Ambato, http://scielo.sld.cu/scielo.php?script=sci_arttext\&pid=S2073$60612016000200003 \& \operatorname{lng}=e s \& t \operatorname{lng}=e s$.

Secretaria Nacional de Planificación y Desarrollo. (2017). Plan Nacional de Desarrollo 2017 2021, Quito.

Stiglitz, J. (2016). La Economía del Sector Público, 4a ed., Antoni Bosch Editor, Barcelona. Trujillo, J. C. (2007). La Constitución económica, más allá neoliberalismo. Revista de Derecho, No. 7, CEN, 111 - 134.

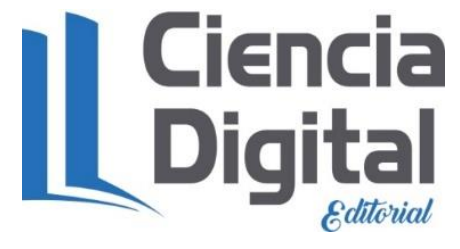


ISSN: 2602-8506

Vol. 4, $\mathrm{N}^{\circ} 1 .$, p.95-115 enero - marzo, 2020

\section{PARA CITAR EL ARTÍCULO INDEXADO}

Morales Noriega, A. M., Chamba Bastidas, L. A., Moreno Lara, J. L., \& Morales Noriega, G. V. (2020). El nuevo modelo económico establecido en el Ecuador. Visionario Digital, 4(1), 95-115. https://doi.org/10.33262/visionariodigital.v4i1.1107

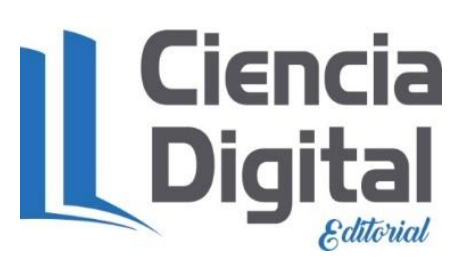

El artículo que se publica es de exclusiva responsabilidad de los autores y no necesariamente reflejan el pensamiento de la Revista Visionario Digital.

El artículo queda en propiedad de la revista y, por tanto, su publicación parcial y/o total en otro medio tiene que ser autorizado por el director de la Revista Visionario Digital.
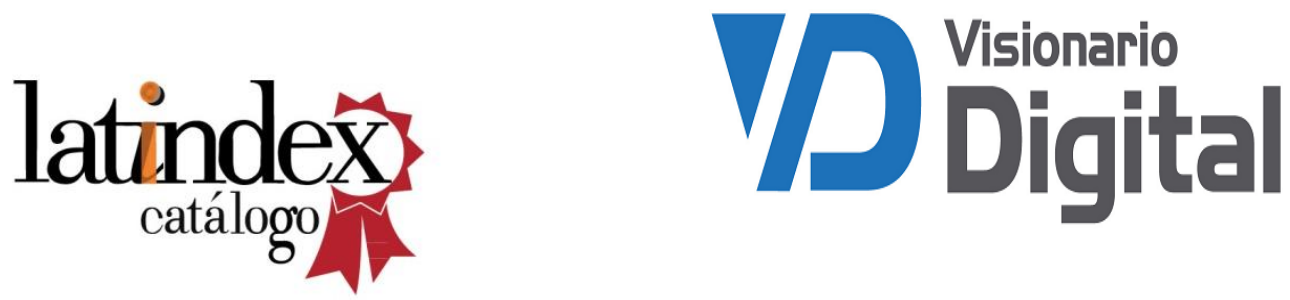